\title{
Convalescent Blood: Current Perspective on the Efficacy of a Legacy Approach in COVID-19 Treatment
}

\author{
Roghayeh Sheervalilou $^{a, b} \quad$ Milad Shirvaliloo $^{c}$ Saman Sargazi $^{b}$ Soraiya Baharid \\ Ramin Saravani $^{b}$ Jafar Shahraki ${ }^{\mathrm{e}}$ Sakine Shirvalilou ${ }^{\mathrm{f}}$ Omolbanin Shahraki ${ }^{\mathrm{a}, \mathrm{b}}$ \\ ${\text { Ziba Nazarloug }{ }^{2} \text { Zinat Shams }}^{\text {h }}$ Habib Ghaznavi ${ }^{a}$

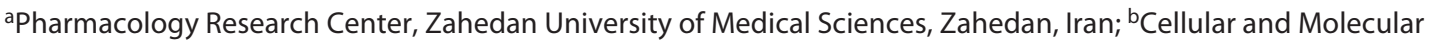 \\ Research Center, Resistant Tuberculosis Institute, Zahedan University of Medical Sciences, Zahedan, Iran; 'Student \\ Research Committee, Tabriz University of Medical Sciences, Tabriz, Iran; ' Genomic Research Center, Shahid Beheshti \\ University of Medical Sciences, Tehran, Iran; 'Department of Toxicology and Pharmacology, School of Pharmacy,

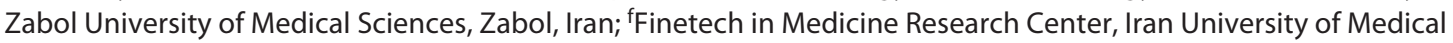 \\ Sciences, Tehran, Iran; ${ }^{9}$ Material Engineering Department, College of Science Koç University, Istanbul, Turkey; \\ hDepartment of Biological Science, Kharazmi University, Tehran, Iran
}

\section{Keywords}

SARS-CoV-2/2019-nCoV/COVID-19 · Therapy · Convalescent blood transfusion · Plasma · Serum (sera)

\begin{abstract}
Since early 2020, COVID-19 has wreaked havoc in many societies around the world. As of the present, the SARS-CoV-2borne disease is propagating in almost all countries, affecting hundreds of thousands of people in an unprecedented way. As the name suggests, the novel coronavirus, widely known as SARS-CoV-2, is a new emerging human pathogen. A novel disease of relatively unknown origin, COVID-19 does not seem to be amenable to the currently available medicines since there is no specific cure for the disease. In the absence of any vaccine or effective antiviral medication, we have no tools at our disposal, but the method of quarantine, be it domestic or institutional, to hinder any further progression of this outbreak. However, there is a record of physicians in the past who practiced convalescent blood transfusion. To
\end{abstract}

their awe, the method seemed to be useful. It is anticipated that these contemporary methods will outdo any other vaccination process in the time being, as blood transfusion is instead a cost-effective and time-friendly technique. Following a successful trial, this new approach of contemporary nature to a viral disease may serve as an emergency intervention to intercept infectious outbreaks and prevent an impending epidemic/pandemic. In this review, we document the most recent evidence regarding the efficiency of convalescent plasma and serum therapy on SARS, MERS, and particularly COVID-19, while discussing potential advantages and possible risks of such practice.

(c) 2021 S. Karger AG, Basel

\section{Introduction}

Following the identification of several patients with an affliction that resembled viral pneumonia, the world faced a downward spiral centered on a local seafood 
wholesale market in Wuhan, China [1]. The pathogen responsible for the instigation of this strange outbreak rapidly rose to global prominence [2], and therefore was named 2019-nCoV by the World Health Organization (WHO) [3]. After further investigations which revealed the true nature of this novel coronavirus, it was unanimously agreed to be named "SARS-CoV-2," which is short for "severe acute respiratory syndrome coronavirus 2." Accordingly, the disease was called "coronavirus disease 2019," further to be simplified to "COVID-19" [4]. As of October 23, over 41,570,883 million confirmed COVID-19 cases and 1,134,940 confirmed deaths were reported to the WHO [5]. The recent outbreak of COVID-19 in China was announced as a public health emergency of international concern by the WHO [4]. On March 11, 2020, the WHO officially proclaimed that the COVID-19 epidemic had become a pandemic [6].

Near 2 decades ago, $>8,000$ patients developed severe acute respiratory syndrome (SARS), a pneumonia-like disease similarly caused by a coronavirus [7]. This was followed by another series of respiratory afflictions about a decade later, which was ultimately revealed to be also due to a coronavirus. The latter, known as Middle East respiratory syndrome (MERS), has been confirmed in 2,494 patients since September 2012 [8, 9]. Interestingly, both SARS and MERS epidemics were caused by virions belonging to the family of $\beta$-coronaviruses [4].

Like its predecessors, SARS-CoV-2 was also recognized as a new member of $\beta$-coronaviruses [2]. This has been confirmed with next-generation sequencing conducted on virions extracted from the respiratory epithelial cells of patients with COVID-19 [10]. The disease has an incubation period spanning 3-7 days [11]. Hallmark symptoms are fever, cough, and fatigue; however, some patients also develop nasal congestion, rhinorrhea, and diarrhea [12]. In severe cases, patients may rapidly deteriorate and develop life-threatening conditions, for example, acute respiratory distress syndrome, septic shock, metabolic acidosis, arrhythmia, and bleeding disorders $[13,14]$. An infection of the lower respiratory tract, SARSCoV-2, manifests with clinical symptoms closest to that of SARS and MERS, albeit milder at the beginning [3]. This is a remarkable distinction, as COVID-19 is demonstrated with mild initial symptoms, even in patients who later develop a critical illness. On computed tomography of the chest, COVID-19 is mostly recognized by groundglass opacities and bilateral patchy infiltrations [15]. From a laboratory point of view, lymphopenia and elevated serum levels of C-reactive protein can be tracked in some patients, but not all of them [16]. Despite being de- cisive, the clinical symptoms and laboratory findings mentioned here are not distinctive since they cannot be easily distinguished from pneumonia caused by pathogens other than SARS-CoV-2 [6].

At the time of writing this article, there is no vaccine for the prevention of SARS-CoV-2 infection [17]. Several countries have already initiated programs for developing an effective vaccine that most likely targets spike glycoprotein as an antigen. Still, given the ample diversity of antigenic variants, it is virtually impossible to provide cross-protection by vaccination, even when all pathogenic strains belong to the same phylogenetic subcluster [18]. That is why the treatment of COVID-19 has been limited to palliative care and respiratory support, that is, oxygen therapy in mild and extracorporeal membrane oxygenation in severe cases [17]. Apart from palliative care, certain therapeutic agents are currently being investigated as potential therapies for COVID-19 [19].

A legacy method, convalescent blood transfusion, might be of value in prevention and even treatment of COVID-19. The biggest challenge here is finding an adequate number of volunteer donors with a history of $\mathrm{CO}$ VID-19 $[20,21]$. Despite all concerns regarding the safety of blood transfusion in terms of SARS-CoV-2 infection, there were no reports of blood-borne SARS-CoV infection back in 2003 [22]. A great portion of therapeutic approaches currently being investigated for their efficacy against COVID-19 are inspired by our experience in treating SARS, MERS, and other viral epidemics [23]. Figure 1 illustrates the convalescent serum therapy procedure (modified from [20]). In this review, we document the most recent evidence regarding the efficiency of convalescent plasma and serum therapy on SARS, MERS, and particularly COVID-19, while discussing potential advantages and possible risks of such practice.

\section{Passive Antibody Therapy}

With a history dating back to the 1890 s, passive antibody therapy was the cornerstone of therapeutic interventions for treating some viral diseases before the advent of antimicrobial therapy in the 1940s [20]. Generally, passive antibody therapy is a more effective method used as a preventive intervention for prophylaxis against diseases, rather than a therapeutic approach for treatment of that illness. In this technique, individuals suspected to be at risk for developing certain ailments are injected with specific antibodies. The antibody incites a relevant immune response that may hinder the occurrence of any 
Fig. 1. The convalescent serum therapy procedure (modified from [20]).

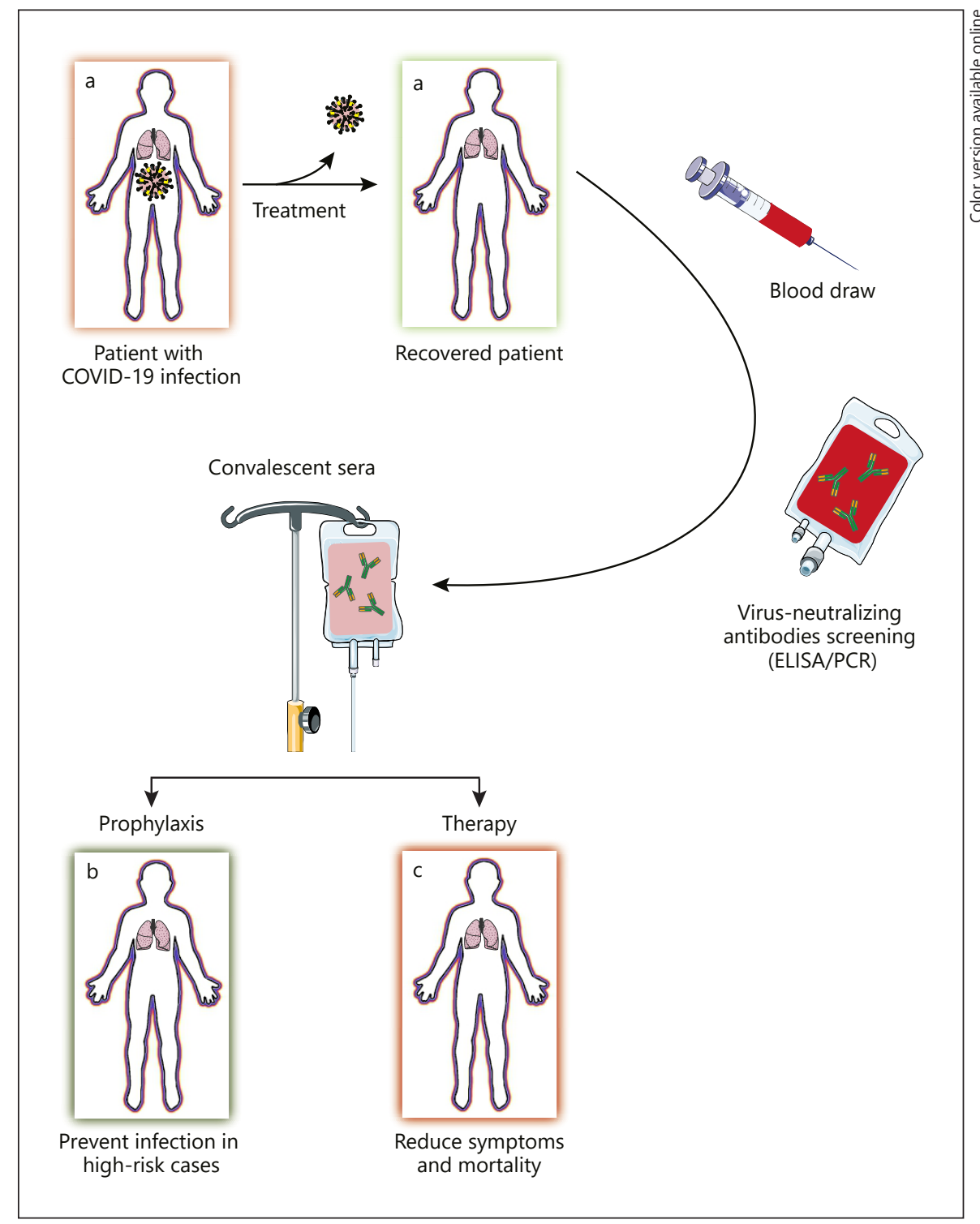

given disease in the future or can further accelerate the function of the immune system when used as a therapeutic approach. Thus, passive antibody administration is the only means of providing immediate immunity to susceptible persons $[24,25]$. In order to be effective, the antibody should be amply injected. When dispensed to a vulnerable individual, this antibody will disseminate in general circulation and reach small capillary beds in different tissues, ultimately inciting a provisional immune response against a particular infection. Protection conferred by the antibody largely depends on its composition and dosage and can last from several weeks to many months [20].

Convalescent Blood for Treatment of COVID-19
According to the experience with other types of coronavirus from the previous outbreaks, such as SARS-CoV, the blood plasma or serum of patients who have surmounted the disease, or are said to be in convalescence, contains neutralizing antibodies against the causative virus [26]. Regarding SARS-CoV-2, it is thought that "viral neutralization" is the primary underlying mechanism through which passive antibody therapy yields protection against the virus. The human convalescent serum is one potential source of antibodies against SARS-CoV-2 extracted from patients who have recovered from COVID-19 [27]. Today, this is the only source that gives immediate access to antibodies against the novel coronavi-

Blood Purif 2022;51:1-14 
rus. In terms of therapy, antibodies are most effective when injected only shortly after the emergence of clinical symptoms. To our knowledge, this is because passive antibody therapy acts through neutralizing the initial inoculum, that is, an aggregate of pathogens limited to an area in the body, which is vastly disseminated once the disease has taken place [28].

\section{History of Blood Therapy}

A legacy method, convalescent serum therapy, held a remarkable place in the early 20th century, when influenza reigned. Despite the variable efficacy depending on the type of the virus, the old-time consensus was that serum therapy worked as a therapeutic intervention [20]. That very same consensus held true almost a century later when clinicians resorted to convalescent serum antibodies to fight against the 2009-2010 H1N1 influenza pandemic. These antibodies, obtained from sera of patients who had recovered, were used for the treatment of severe $\mathrm{H} 1 \mathrm{~N} 1$ influenza in patients under intensive care [29]. As of the new millennium, a lack of effective therapies for the 2 relatively menacing coronavirus epidemics, that is, SARS and MERS, led to the practice of serum therapy on certain patients [30].

According to the anecdotal evidence, all patients who had received human convalescent serum survived, suggesting that the legacy method was a successful approach. Although one must not overlook subtle dissimilarities in different viral infections, our recent memory reminds us of the promising results achieved with serum therapy, making it a powerful method of approach when COVID-19 is wreaking havoc in a myriad of societies [20].

\section{Convalescent Plasma}

Similar to previous viral epidemics, passive immunotherapy by transfusion of convalescent plasma is yet considered a promising approach toward the treatment of severely ill patients with COVID-19 [31]. This arguably old-fashioned method becomes even more apposite as one subtilizes the egregious lack of vaccines and medicines required for successful treatment of COVID-19 [32]. Given the route of administration, the efficacy of convalescent plasma therapy can be explained by the immediate access of antibody molecules to virions disseminated in general circulation. Immunoglobulin-rich convalescent plasma was once regarded as a last resort in treating SARS, mostly indicated for critically ill patients who did not respond well to methylprednisolone. Several studies have reported that recipients of convalescent plasma not only presented a lower mortality rate but also had a shorter hospital stay compared to patients who did not receive such care [19].

\section{Convalescent Serum}

Blood serum is obtained when plasma is stripped of its fibrinogen, a coagulation factor that readily aggregates upon clot formation. Normally, fibrinogen has a concentration of $<4 \mathrm{~g} / \mathrm{L}$ in the blood [33]. Fibrinogen concentration can further rise in the blood of elderly COVID-19 patients, who also have underlying health conditions in many instances. This concentration can be as high as 8-12 g per $400 \mathrm{~mL}$, duly evidenced with the blood obtained from elderly donors for transfusion to severely ill COVID-19 patients. Despite being incapable of inciting a graft versus host reaction, the donor's fibrinogen is still considered a foreign antigen by the recipient's immune system, especially when received in large amounts. The excess foreign material is thus removed from the recipient's blood at the expense of macrophages and $\mathrm{T}$ cells that would otherwise mediate an immune response against SARS-CoV-2. Therefore, a fibrinogen-laden plasma not only does not improve the condition of ill patients but also incapacitates their immune system. Accordingly, the foreign fibrinogen macromolecules must be removed to avoid the development of allergy or any undesirable effect on treatment. This revised form of passive immunotherapy has been named "serum therapy" due to its refined nature [34] and can be safely utilized for the treatment of COVID-19 patients in intensive care units [31].

A large number of patients who recover from $\mathrm{CO}$ VID-19 produce specific antibodies against the causative agent [34]. This makes their serum a valuable asset for hindering reinfection with SARS-CoV-2. While serving as preventive agents, antibodies can also decelerate the reproduction of the virus in the acute phase of COVID-19, pruning the twisted course of the disease [29].

\section{Studies on Convalescent Plasma and Serum Therapy}

Table 1 explains details of the studies about convalescent plasma and serum therapy on patients with $\mathrm{CoV}$.

\section{SARS and MERS}

A clinical trial on 80 patients with SARS amid the outbreak in 2002-2003, Hong Kong, found that patients who received human convalescent serum within 2 weeks from the onset of their symptoms were more likely to be discharged from the hospital than patients who were not treated as such [30]. A year following the SARS outbreak, 
a retrospective analysis concluded that convalescent plasma therapy had a more desirable impact on both patient survival rate and duration of hospital stay, compared to the outcomes achieved with high doses of methylprednisolone [35]. Another investigation conducted on convalescent plasma obtained from SARS patients in 2005 reported that 87 out of 99 samples contained neutralizing antibodies. A geometric mean titer of 1:61 was also measured for this antibody [26]. These findings suggested that, in reality, few patients retain a high titer of neutralizing antibodies, as these molecules are gradually worn out over time. The study also implied that there might be a good chance that these patients also produced nonneutralizing antibodies, which further helped their immune system to keep the infection contained [20]. Table 1 lists studies on SARS therapy through convalescent plasma.

Published in 2014, a meta-analysis on clinical outcomes of convalescent plasma therapy in the treatment of SARS and MERS further emphasized the desirable effects of this method on mortality rate and viral load of such respiratory infections. This study reported promising clinical outcomes in terms of mortality among patients with different kinds of severe acute respiratory infection who had received variable doses of convalescent plasma [32]. The following year, scientists in Guinea reported an inconclusive attempt to evaluate convalescent plasma therapy in treating patients with MERS. This investigation could not bring reliable data on the table since it failed to look for high levels of neutralizing antibodies in patients. It was speculated that the study could lead to more conclusive findings had it been conducted on patients who were at earlier stages of their disease, rather than individuals who had already been fighting MERS for an extended period [36]. Further progress was made in the same year, as an official protocol was published to apply convalescent plasma in the treatment of MERS in 2015 [37]. Lastly, a more recent study in 2016 corroborated the efficacy of convalescent plasma therapy when applied within a short period following the onset of clinical symptoms. The study also asserted that not all recovering MERS patients displayed high titers of neutralizing antibodies in their blood, regarding it as a challenge in the clinical practice of this approach [38].

\section{COVID-19}

As for the ongoing SARS-CoV-2 pandemic, there have been reports that China, as the country of origin with a staggering number of patients, approved convalescent serum to be used for treating several patients. For this matter, an interventional study on 10 COVID-19 patients confirmed the safety of convalescent plasma transfusion and reported significant improvement in clinical conditions and lab findings of these patients. The study concluded that convalescent plasma therapy was very well tolerated by the patients and thus could be considered a prospective approach for neutralizing viremia in patients with severe disease [39]. Soon after, 2 separate trials reported similar results with convalescent serum therapy on 4 [40] and 5 [41] critically ill patients who had been diagnosed with COVID-19. The beneficial effects of convalescent plasma were not only restricted to younger patients, as scientists in China were able to successfully treat an elderly patient who was over 100 years old. After every single attempt resulted in failure, the centenarian patient was administered with convalescent plasma, which led to a decrease in the serum viral load [42]. Such clinical improvements were also observed with the radiological findings in patients with COVID-19, who had opted to receive convalescent plasma [43]. Shortly, Korea published its very first report on the successful application of convalescent blood products along with corticosteroids for treating severe pneumonia associated with COVID-19 [44]. However, further investigations did not find this technique useful.

One particular randomized clinical trial, published in June 2020, sought to investigate the potential effects of convalescent plasma therapy on the time of clinical improvement, only to find out that this treatment modality did not result in any statistically significant difference in the clinical condition of patients, compared to the standard treatment regimen. It was argued that maybe the early termination of the study after only 28 days was the reason for such unfavorable results [45]. Salazar et al. [46], in their study on patients $(n=25)$ with severe and/ or life-threatening COVID-19 disease, reported safety as the primary study outcome and clinical status as the secondary outcome at day 14 posttransfusion. Comparably, another study conducted on 6 patients with respiratory failure concluded that transfusion of convalescent plasma might reduce the shedding of the virus. Still, it could not improve the survival of end-stage patients with COVID-19. The eventual death of 5 patients in this study indicated that such therapeutic measures should have been taken well before the progression of the disease to respiratory failure [47].

From that day forward, several other reports have been published on the promising results achieved with plasma therapy in the treatment of COVID-19. For instance, a group of physicians in the USA saved a 30-year-old pregnant patient with simultaneous administration of conva- 


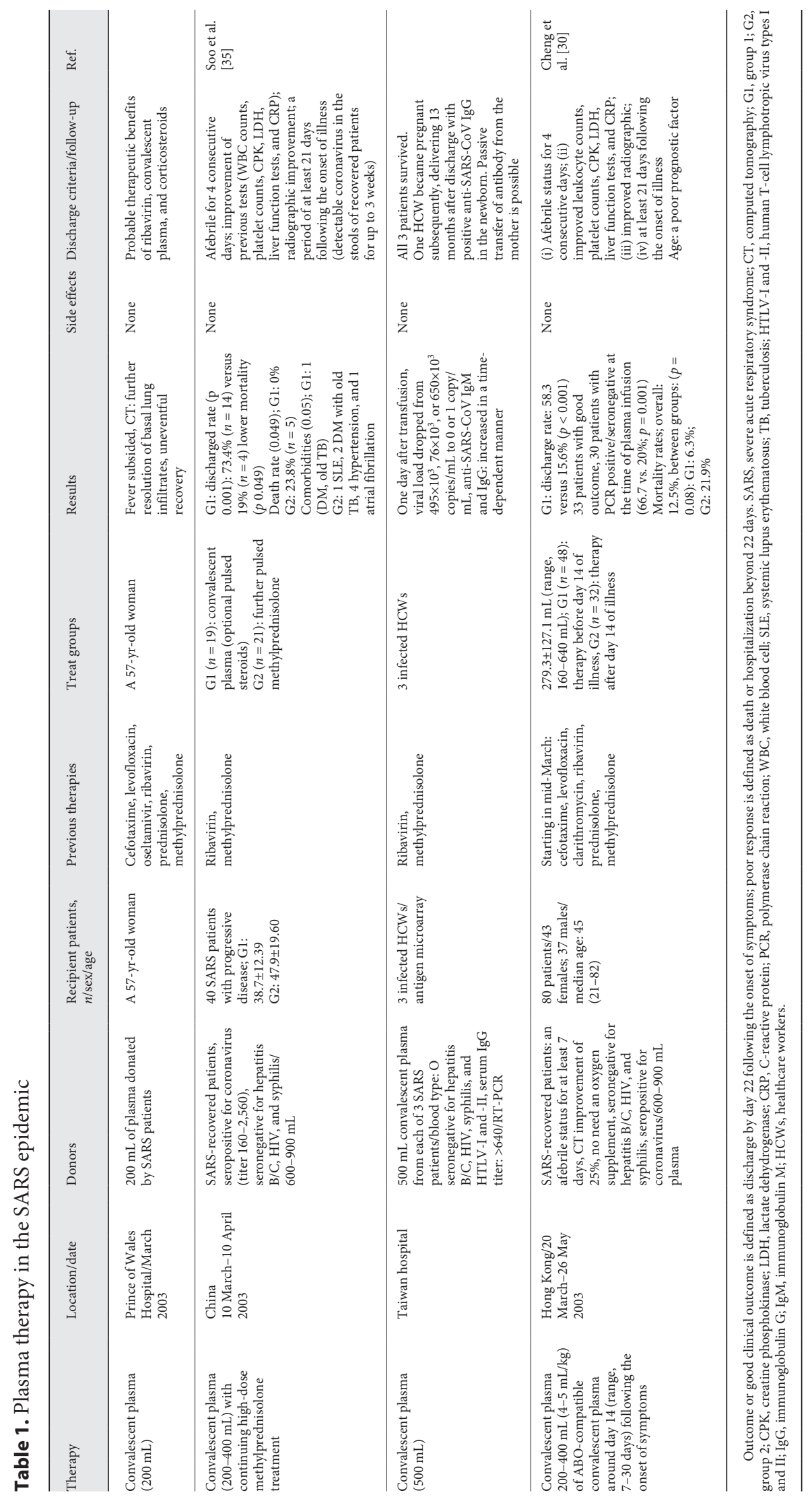


lescent plasma and remdesivir [48]. Another patient with COVID-19 in China substantially improved after being treated with plasma containing high titers of IgM and IgG. According to this report, the patient no longer required mechanical ventilation on the eleventh day following plasma transfusion [49]. A recently published systematic review deemed convalescent plasma therapy a safe and effective treatment modality [50]. The technique has also been suggested to be a life-saving approach in treating COVID-19 patients with liver dysfunction or diabetes [51]. Table 2 lists the studies on COVID-19 therapy through convalescent plasma.

Being the most populated country in the world, it should not come as a surprise that China could secure ample plasma samples from donors, most of whom were volunteers who had recovered from COVID-19. The country also put great effort into the detection and extraction of viral antigens and antibodies to each of them, thus accelerating the manufacture of diagnostic kits for timely detection of the infection [34].

It is thought that specific antibodies should bind the SARS-CoV-2 spike protein and neutralize the virions, preventing further infection of intact cells [21]. However, an appropriate titer of such antibody is yet to be determined [52]. Given the theoretically high efficacy of the method, it remains unclear whether an adequate pool of volunteer donors can be sustained. Past work on MERS-CoV appalled scientists on this very ground, as the verdict was that human convalescent serum did not contain the minimal therapeutic titer of antibody required for treatment of patients [37]. Viremia, the presence of virions in blood, usually occurs in the first week following a viral infection. Since this statement holds true for many viral infections, convalescent plasma therapy would be most effective at the early stage of such diseases [53].

\section{The US Food and Drug Administration}

Clinical application of plasma collected from recovered patients has recently been approved by the US Food and Drug Administration (FDA) to treat COVID-19, albeit on certain conditions. Despite being a less commonly used method, convalescent plasma therapy has been adopted to treat ailments, such as the 1918 Spanish flu, polio, measles, mumps, and several respiratory infections, throughout history. A long-studied last resort, plasma therapy was an entirely plausible option that could not possibly be overlooked by the New York officials, as they permitted clinical trial of this technique on severely ill patients in the state. This, in turn, prompted the FDA

Convalescent Blood for Treatment of COVID-19 to issue their official approval regarding the clinical application of convalescent plasma that requires several conditions to be met [54]. Table 3 lists the FDA requirements for the donation of convalescent plasma for $\mathrm{CO}$ VID-19 [55].

\section{Required Conditions for Blood Product Therapy}

The official large-scale practice of convalescent blood product therapy on COVID-19 patients is only approved, provided that specific prerequisites are met [20]: (1) access to a sufficiently large community of donors who have recently recovered from COVID-19; (2) convenience of special facilities for storing and processing of the collected blood; (3) accessibility of both serological and virological assays for precise detection and measurement of SARS-CoV-2 virions in the blood; (4) a reliable platform for priming of all lab tests; (5) authentic protocols for prophylaxis and treatment that are established based on findings reported by clinical trials; and (6) regulatory compliance that may vary by institution or location. Hence, the proper application of this technique requires a multitude of different centers, working unanimously on delivering a well-grounded treatment for patients under intensive care [56].

\section{Benefits}

Convalescent plasma/serum can mutually be used for prophylaxis against SARS-CoV-2 infection and treatment of COVID-19 [20]. When taken as a prophylactic measure, this method can be of great benefit to individuals who are more susceptible to this infection. If hesitant, convalescent sera can also be administered for symptomatic patients in hopes of palliating the most obstinate symptoms, concomitantly alleviating the ultimate risk of death. Based on our knowledge of antibody-containing serum therapy, it is strongly recommended to utilize this method as a preventive action in due time, rather than resort to it as a remedial potion when it is not as effective [57].

\section{Potential Risks}

Treatment with human immunoglobulin has conferred a nonnegligible increased risk of thrombotic events [58]. For this reason, potential benefits of immunoglobu- 


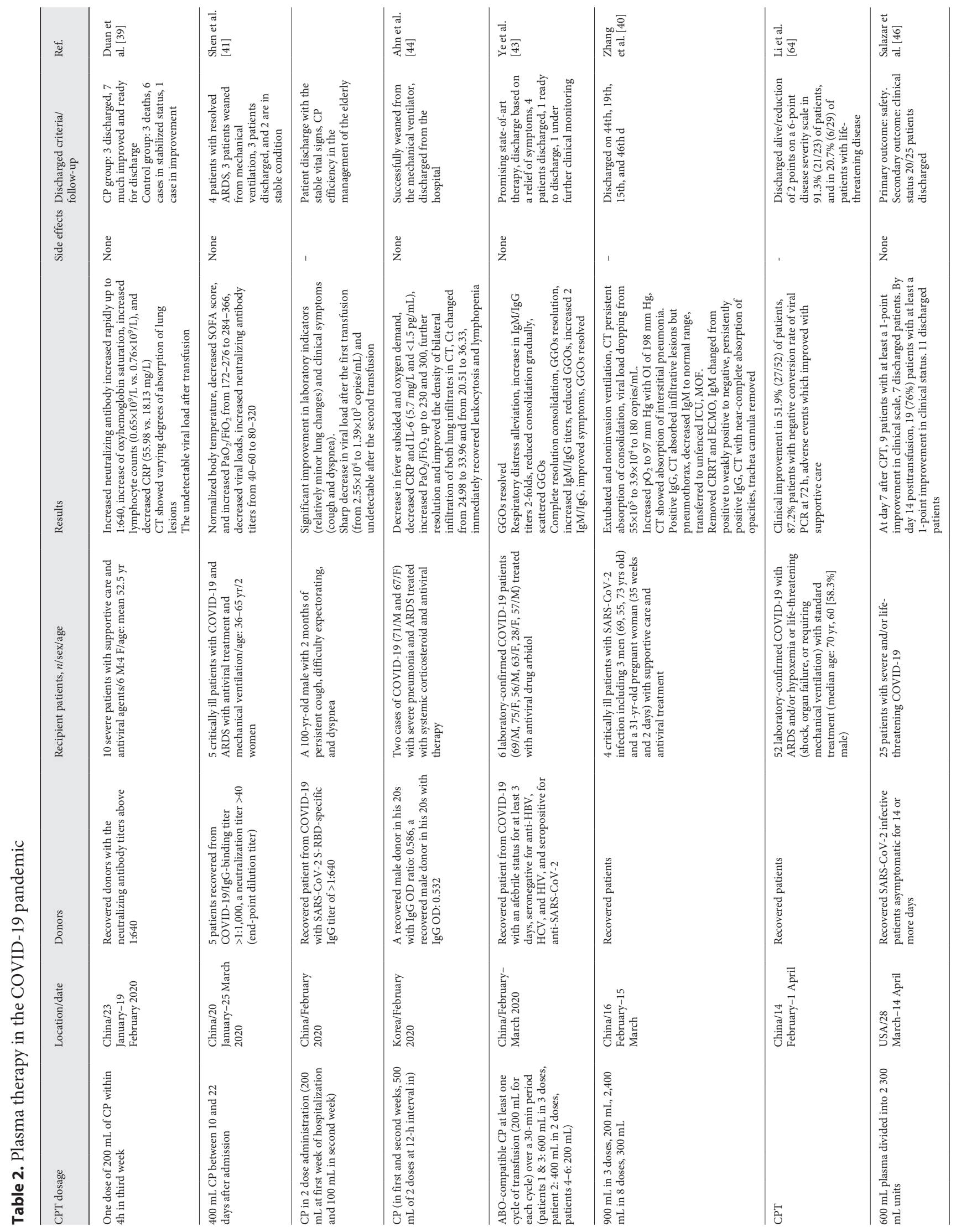




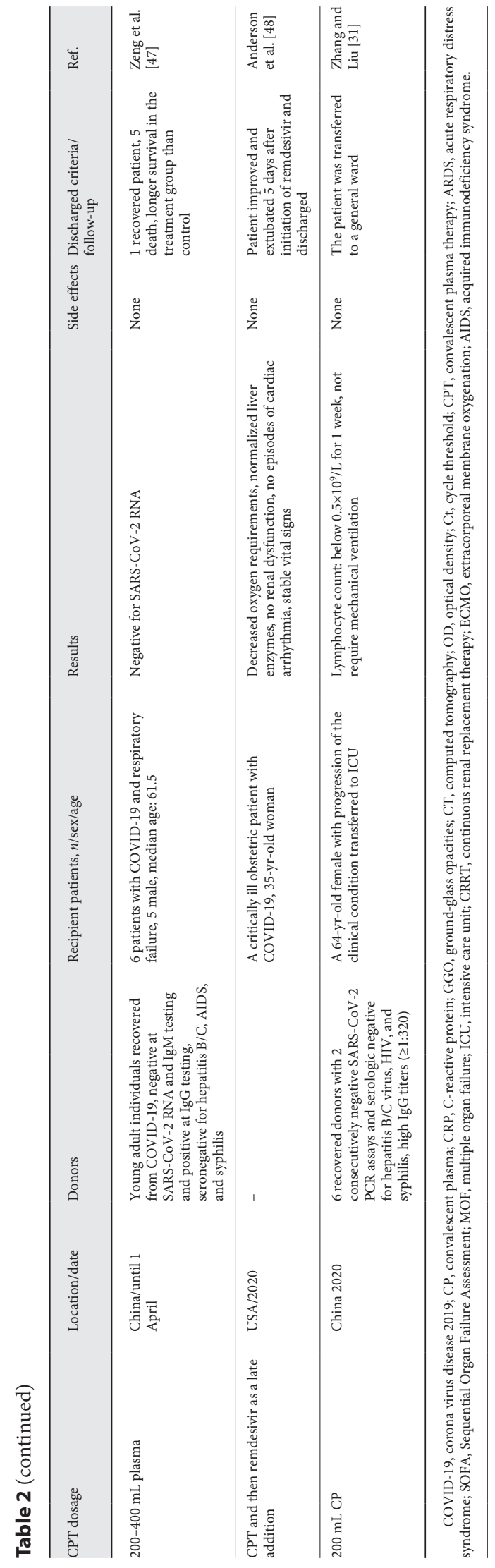

Convalescent Blood for Treatment of COVID-19

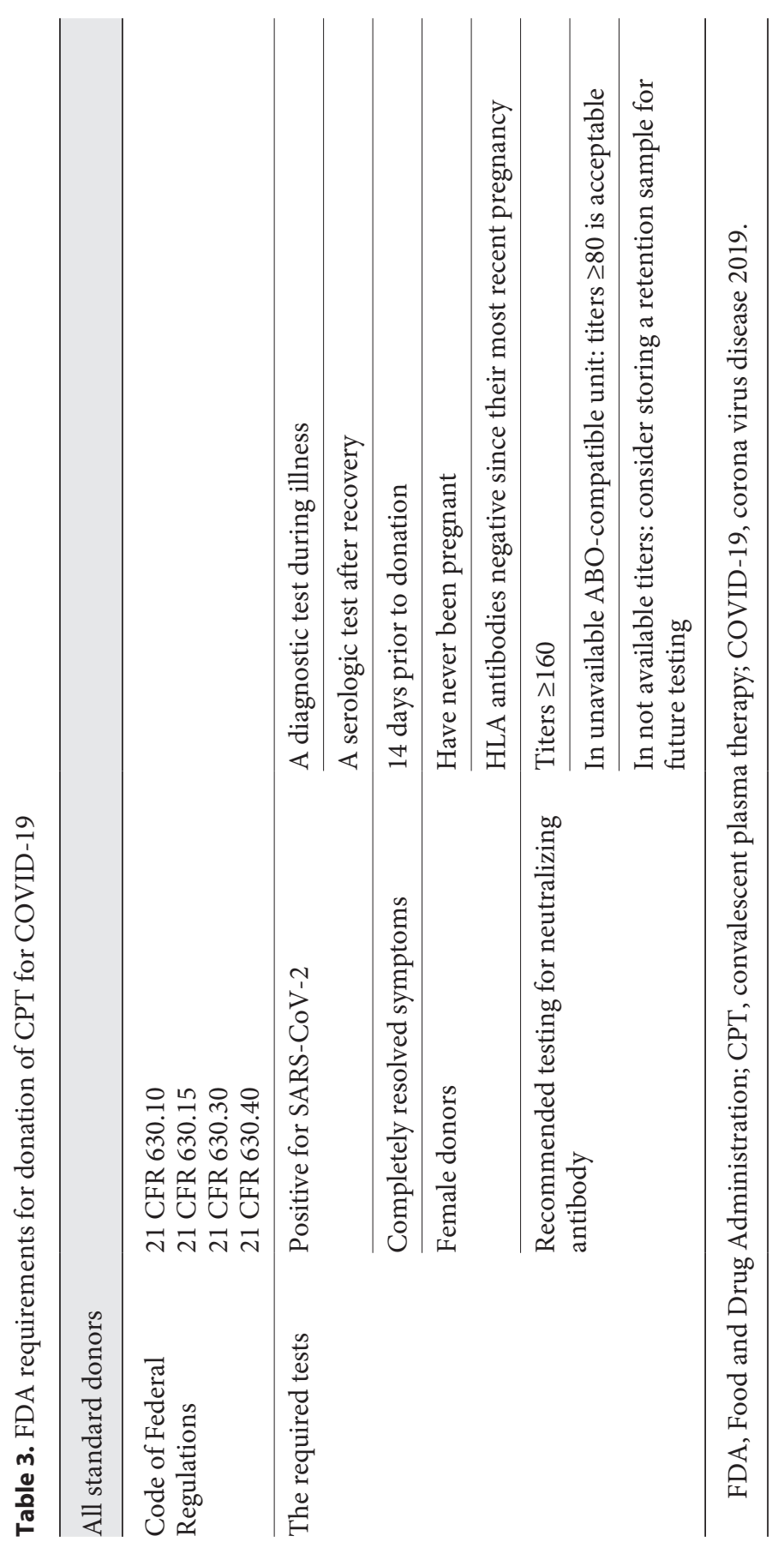

Blood Purif 2022;51:1-14

DOI: $10.1159 / 000513164$ 
lin therapy should be carefully assayed, and intervention must only take place when the benefits outweigh possible risks. Since the entire biology of the novel coronavirus is unbeknownst to us, it would be a wise strategy to locally collect convalescent plasma and administer it only to patients who have contracted COVID-19 from the same community. This could be the most valid option yet, as it minimizes the risk of incompatibility between the antibody and causative strain [21].

Convalescent serum therapy spawns an array of risks that fall into 2 major categories: known and theoretical [20]. Known risks are well-studied adverse events associated with transfusion of blood products, on top of which stands the risk of inadvertent blood-borne infection. Hypersensitivity and immune reactions to blood constituents is another menacing risk. Following the advent of modern and precise techniques for screening of blood-borne pathogens and cross-matching procedures, such risks have been rendered virtually nonexistent. Nevertheless, known risks are not only limited to common events, as some patients with pulmonary diseases may develop rare conditions such as transfusionrelated acute lung injury shortly after the transfusion. Since COVID-19 is a potentially life-threatening pulmonary disease, any convalescent serum must be rigorously screened and cross-matched before it is administered to patients [59].

As for theoretical risks, antibody-dependent enhancement of infection (ADE) is one such incident. Caused by exposure to specific antibodies, ADE is a condition in which the underlying disease is aggravated following parenteral treatment with an antibody. In the case of coronaviruses, it is speculated that exposure to antibodies specific to one strain might provoke infection with another strain [60]. However, ADE is unlikely to occur in this scenario, as convalescent serum preparations are exclusively produced against the same strain responsible for the pandemic. Pieces of evidence on the previous application of serum therapy in the treatment of SARS and MERS [61] strongly support the safety of this modality.

It is also possible that treatment with exogenous antibodies would incapacitate the immune system, leading to catastrophic consequences in individuals who had previous exposure to SARS-CoV-2. In this context, several studies have indicated that passive immunotherapy via antibodies before vaccination against the respiratory syncytial virus might leave a negative impact on humoral immunity, but not cellular [62].

\section{Ethics}

Issues to be considered in this context are the lack of reliable and comprehensive studies on this subject and the far-fetched convenience of adequate volunteer donors with a high titer of neutralizing antibodies in their blood [58]. Since humans are the source of antibodies in this therapeutic modality, all processes involved in serum preparation must be carefully monitored with due attention to the ethical protocols issued by the institutes [63].

\section{Conclusions}

Based on the guidelines by the WHO, primary prevention stands on the pinnacle of strategies adopted for the management of the COVID-19 outbreak, with monitoring, screening for suspected cases, and supportive care following. Lack of reliable evidence is the primary reason behind the absence of specific treatments. To overcome this disastrous situation, research and development programs should urgently be initiated to find effective therapies to halt the ever-growing chain of the infection efficiently.

Convalescent plasma/serum has been confirmed to be of therapeutic value by several studies, without leaving any major adverse effects on patients with viral diseases. Immunotherapy through transfusion of neutralizing antibodies might be an effective method in the prevention of new infections. Based on our experience with devastating outbreaks such as influenza, SARS, and MERS, immunotherapy through transfusion of convalescent plas$\mathrm{ma}$ /serum obtained from recovered patients with high titers of neutralizing antibodies in their circulation might be helpful to reduce viral load and mortality rate. Therefore, it is sensible to allocate enough manpower for efficacy and safety assessment of convalescent plasma therapy in treating COVID-19.

\section{Future Perspectives}

1. In every case that human convalescent plasma/serum therapy is indicated, expected benefits and potential risks must be weighed against each other to make a conclusive decision for treatment of patients.

2. With more safety and higher potency, purified antiSARS-CoV-2 immunoglobulin-rich preparations are considered better options in terms of therapy, as opposed to convalescent sera collected from recovered
Sheervalilou et al. 
patients. Nonetheless, numerous challenges must be overcome for the ultimate consideration of convalescent plasma as a good therapeutic option. To name a few, on-demand access to a well-stocked supply of donor samples, a careful review of clinical conditions specific to each patient, having a basic understanding of viral kinetics, and host immune response to SARSCoV-2 are all major challenges that need to be confronted.

3. Caution and discretion are strongly advised in clinical trials on convalescent sera, as the slightest likelihood of risk occurrence, be it known or theoretical, must be identified and addressed.

\section{Other Recent Developments in the Management of COVID-19}

In the meanwhile, there has also been a number of other recent developments, aside from immunotherapy, aimed at treatment of COVID-19 [2, 64-69].

\section{Admission to the Intensive Care Unit and Subsequent} Isolation and Quarantine Measures

It is strongly advised that suspected cases with equivocal findings be isolated from other individuals and subsequently be quarantined in a single room. Patients with a definitive diagnosis of COVID-19 can be admitted to the same isolated ward and treated accordingly. Patients with severe disease, on the other hand, need to be hospitalized in the intensive care unit and undergo immediate treatment [64].

\section{General Treatments}

As the term might suggest, general treatment strategies encompass a broad array of inpatient and outpatient interventions that are not solely aimed at patients who meet certain criteria, but rather are recommended to all patients with symptomatic disease. These strategies include rest at home, intravenous administration of methylprednisolone and/or adrenaline, adequate energy intake, maintenance of homeostasis (balance between the level of water and electrolytes in the body), and monitoring of vital signs (pulse rate, respiratory rate, blood pressure, body temperature, oxygen saturation, and pain) $[64,66]$.

Drugs

Antiviral Therapies

A diverse number of antiviral medications have been considered in the treatment of COVID-19. The most no- table examples are IFN- $\alpha$ (induction of resistance to viral infection in prospective host cells) [70], lopinavir/ritonavir and darunavir (HIV-1 protease inhibitors) $[67,71]$, ribavirin (viral nucleosidase inhibitor) [72], umifenovir/ arbidol and favipiravir (inhibition of viral entry to the target cell) [73], remdesivir (termination of viral replication) [74], and oseltamivir (neuraminidase inhibitor) [66]. The results of recent clinical trials have supported the potential clinical efficacy of these antiviral medications to some extent, especially remdesivir, lopinavir/ ritonavir, and favipiravir [69].

Immunosuppressive Therapy

Tocilizumab and sarilumab are 2 humanized and human monoclonal antibodies, respectively, that inhibit IL-6 receptors. These antibodies have shown promise in the treatment of COVID-19 in patients with certain conditions $[67,75]$.

\section{Antibiotic Therapy}

Intramuscular and/or intravenous administration of antibiotics such as moxifloxacin may be an effective method for prevention of secondary bacterial infection in patients with COVID-19, as some studies suggest [66].

\section{Cellular Therapy}

With their evidence-based therapeutic implications in acute lung injury and acute respiratory distress syndrome, mesenchymal stem cells can potentially reverse the process of fibrosis and accelerate tissue repair in the lungs by alleviating the excess secretion of proinflammatory cytokines and inhibiting the infiltration of immune cells to the pulmonary tissue $[76,77]$. On a more factual and idiosyncratic level, there are human neutral killer cells as part of the cell-mediated immunity that can recognize antibodycoated virus-infected cells and digest them during an elaborate process called antibody-dependent cellular cytotoxicity [78].

\section{Traditional Medicine}

An apropos representative of traditional medicine, Chinese herbal medicine, has long recognized certain compounds with specific characteristics that might be of therapeutic value in the case of COVID-19. Herbal compounds with potential indications in the treatment of COVID-19 may include glycyrrhizin and hesperetin, potential inhibitors of viral entry associated with molecular pathways pertaining to membrane lipid rafts [79] and transmembrane ACE2 [80]; quercetin, another compound with inhibitory effects on viral entry through the 
blocking of 3CLpro of SARS-CoV [81, 82]; and baicalin, known for its potential antiviral activity [83].

\section{Nanobiotechnology}

An insidious pathology of viral origin, HIV infection, has been reported to be responsive to specific nanoparticles conjugated with antiviral agents, especially nucleoside analogs. Today, there is an ample number of nanotechnology-based drug delivery platforms that can be experimentally adopted for the treatment of COVID-19 with specific therapeutic compounds as conjugates, in hopes of alleviating the symptoms of COVID-19 and shortening the natural course of this notorious malady [2].

\section{Acknowledgements}

This review was conducted under the supervision of the Zahedan University of Medical Sciences and the Iran University of Medical Sciences.

\section{Conflict of Interest Statement}

The authors declare that they have no conflicts of interest.

\section{Funding Sources}

This review was financially supported by the Zahedan University of Medical Sciences and the Iran University of Medical Sciences (Grant No. IR.ZAUMS.REC.1399.197).

\section{Author Contributions}

All authors contributed to this project. Roghayeh Sheervalilou, Milad Shirvaliloo, and Sakine Shirvalilou designed this study. Soraiya Bahari, Ziba Nazarlou, and Zinat Shams conducted a literature search. Dr. Jafar Shahraki and Omolbanin Shahraki validated and interpreted the results. Roghayeh Sheervalilou, Milad Shirvaliloo, and Saman Sargazi drafted the manuscript. Dr. Habib Ghaznavi and Ramin Saravani reviewed and edited. Dr. Habib Ghaznavi, Roghayeh Sheervalilou, Milad Shirvaliloo, and Saman Sargazi revised the manuscript. All the authors read through the manuscript and agreed to the submission of the final version.

\section{References}

1 Li Q, Guan X, Wu P, Wang X, Zhou L, Tong $\mathrm{Y}$, et al. Early transmission dynamics in $\mathrm{Wu}-$ han, China, of novel coronavirus-infected pneumonia. N Engl J Med. 2020 Mar 26; 382(13):1199-207.

2 Sheervalilou R, Shirvaliloo M, Dadashzadeh N, Shirvalilou S, Shahraki O, Pilehvar-Soltanahmadi Y, et al. COVID-19 under spotlight: a close look at the origin, transmission, diagnosis, and treatment of the $2019-\mathrm{nCoV}$ disease. J Cell Physiol. 2020 Dec;235(12):8873924.

3 Huang C, Wang Y, Li X, Ren L, Zhao J, Hu Y, et al. Clinical features of patients infected with 2019 novel coronavirus in Wuhan, China. Lancet. 2020;395(10223):497-506.

4 Chang L, Yan Y, Wang L. Coronavirus disease 2019: coronaviruses and blood safety. Transfus Med Rev. 2020 Apr;34(2):75-80.

5 Available from: https://www.who.int/ data\#reports.

6 Zhao J, Yuan Q, Wang H, Liu W, Liao X, Su $\mathrm{Y}$, et al. Antibody responses to SARS-CoV-2 in patients of novel coronavirus disease 2019. Clin Infect Dis. 2020 Nov 19;71(16):2027-34.

7 Saif L. Animal coronaviruses: What can they teach us about the severe acute respiratory syndrome? Rev Sci Tech. 2004;23(2):643-60.

8 World Health Organization. Summary of probable SARS cases with onset of illness from 1 November 2002 to 31 July 2003. 2020. Accessed 2020 May 2. Available from: https:// www. who.int/csr/sars/country/table2004_04_21/en/; 2004.
9 World Health Organization. Middle East respiratory syndrome coronavirus (MERSCoV). 2020. Accessed 2020 May 2. Available from: https://www.who.int/emergencies/ mers-cov/en/; 2013.

10 Zhu N, Zhang D, Wang W, Li X, Yang B, Song $\mathrm{J}$, et al. A novel coronavirus from patients with pneumonia in China, 2019. N Engl J Med. 2020 Feb 20;382(8):727-33.

11 Guan W-j, Ni Z-y, Hu Y, Liang W-h, Ou C-q, He J-x. Clinical characteristics of 2019 novel coronavirus infection in China. medRxiv. 2020;10:

12 Wang $\mathrm{M}, \mathrm{Wu} \mathrm{Q}, \mathrm{Xu}$ W, Qiao B, Wang J, Zheng $\mathrm{H}$, et al. Clinical diagnosis of 8274 samples with 2019-novel coronavirus in Wuhan. medRxiv. 2020

13 Chen N, Zhou M, Dong X, Qu J, Gong F, Han $\mathrm{Y}$, et al. Epidemiological and clinical characteristics of 99 cases of 2019 novel coronavirus pneumonia in Wuhan, China: a descriptive study. Lancet. 2020;395(10223):507-13.

14 Wu C-I, Postema PG, Arbelo E, Behr ER, Bezzina CR, Napolitano C, et al. SARS-CoV-2, COVID-19 and inherited arrhythmia syndromes. Heart Rhythm. 2020 Sep;17(9): 1456-62.

15 Wang D, Hu B, Hu C, Zhu F, Liu X, Zhang J, et al. Clinical characteristics of 138 hospitalized patients with 2019 novel coronavirus-infected pneumonia in Wuhan, China. JAMA. 2020 Mar 17;323(11):1061-9.
16 Wan S, Yi Q, Fan S, Lv J, Zhang X, Guo L, et al. Characteristics of lymphocyte subsets and cytokines in peripheral blood of 123 hospitalized patients with 2019 novel coronavirus pneumonia (NCP). Medrxiv. 2020.

17 L-s W, Wang Y-r, Ye D-w, Liu Q-q. A review of the 2019 Novel Coronavirus (COVID-19) based on current evidence. Int J Antimicrob Agents. 2020 Sep;56(3):106137.

18 Graham RL, Donaldson EF, Baric RS. A decade after SARS: strategies for controlling emerging coronaviruses. Nat Rev Microbiol. 2013;11(12):836-48.

19 Chen L, Xiong J, Bao L, Shi Y. Convalescent plasma as a potential therapy for COVID-19. Lancet Infect Dis. 2020 Apr;20(4):398-400.

20 Casadevall A, Pirofski L-a. The convalescent sera option for containing COVID-19. J Clin invest. 2020 Apr 1;130(4):1545-48.

21 Cunningham AC, Goh HP, Koh D. Treatment of COVID-19: old tricks for new challenges. Springer; 2020.

22 World Health Organization. WHO recommendations on SARS and blood safety. 2020 Accessed 2020 May 2. Available from: https:// www.who.int/csr/sars/guidelines/bloodsafety/en/; 2003.

23 Dhama K, Sharun K, Tiwari R, Sircar S, Bhat S, Malik YS, et al. Coronavirus disease 2019COVID-19. 2020.

24 Casadevall A, Scharff MD. Return to the past: the case for antibody-based therapies in infectious diseases. Clin Infect Dis. 1995;21(1): $150-61$. 
25 Casadevall A, Dadachova E, Pirofski L-a. Passive antibody therapy for infectious diseases. Nat Rev Microbiol. 2004;2(9):695-703.

26 Zhang JS, Chen JT, Liu YX, Zhang ZS, Gao H, Liu Y, et al. A serological survey on neutralizing antibody titer of SARS convalescent sera. J Med Virol. 2005;77(2):147-50.

27 Beigel JH, Voell J, Kumar P, Raviprakash K, $\mathrm{Wu} \mathrm{H}$, Jiao JA, et al. Safety and tolerability of a novel, polyclonal human anti-MERS coronavirus antibody produced from transchromosomic cattle: a phase 1 randomised, double-blind, single-dose-escalation study. Lancet Infect Dis. 2018;18(4):410-8.

28 Robbins JB, Schneerson R, Szu SC. Perspective: hypothesis: serum IgG antibody is sufficient to confer protection against infectious diseases by inactivating the inoculum. J Infect Dis. 1995; 171(6): 1387-98.

29 Hung IF, To KK, Lee CK, Lee KL, Chan K, Yan WW, et al. Convalescent plasma treatment reduced mortality in patients with severe pandemic influenza A (H1N1) 2009 virus infection. Clin Infect Dis. 2011;52(4):44756.

30 Cheng Y, Wong R, Soo YO, Wong WS, Lee $\mathrm{CK}, \mathrm{Ng} \mathrm{MH}$, et al. Use of convalescent plasma therapy in SARS patients in Hong Kong. Eur J Clin Microbiol Infect Dis. 2005;24(1):44-6.

31 Zhang L, Liu Y. Potential interventions for novel coronavirus in China: a systematic review. J Med Virol. 2020 May;92(5):479-90.

32 Mair-Jenkins J, Saavedra-Campos M, Kenneth Baillie J, Cleary P, Khaw F-M, Lim WS. The effectiveness of convalescent plasma and hyperimmune immunoglobulin for the treatment of severe acute respiratory infections of viral etiology: a systematic review and exploratory meta-analysis. 2015 Jan 1 [cited 2020 Feb 15];211(1):80-90.

33 McQuilten ZK, Wood EM, Bailey M, Cameron PA, Cooper DJ. Fibrinogen is an independent predictor of mortality in major trauma patients: a five-year statewide cohort study. Injury. 2017;48(5):1074-81.

34 Law PK. Emergent serum therapy and antibody medicine to counteract sudden attacks of COVID-19 and other pathogenic epidemics. Scientific Research Publishing; 2020.

35 Soo YO, Cheng Y, Wong R, Hui DS, Lee CK, Tsang KK, et al. Retrospective comparison of convalescent plasma with continuing highdose methylprednisolone treatment in SARS patients. Clin Microbiol Infect. 2004;10(7): 676-8.

36 Available from: https://www.who.int/emergencies/diseases/novel-coronavirus-2019/situation-reports.

37 Arabi Y, Balkhy H, Hajeer AH, Bouchama A, Hayden FG, Al-Omari A, et al. Feasibility, safety, clinical, and laboratory effects of convalescent plasma therapy for patients with Middle East respiratory syndrome coronavirus infection: a study protocol. Springerplus. 2015;4(1):709-8.
38 Arabi YM, Hajeer AH, Luke T, Raviprakash $\mathrm{K}$, Balkhy H, Johani S, et al. Feasibility of using convalescent plasma immunotherapy for MERS-CoV infection, Saudi Arabia. Emerging Infect Dis. 2016;22(9):1554.

39 Duan K, Liu B, Li C, Zhang H, Yu T, Qu J, et al. Effectiveness of convalescent plasma therapy in severe COVID-19 patients. Proc Natl Acad Sci U S A. 2020;117(17):9490-6.

40 Zhang B, Liu S, Tan T, Huang W, Dong Y, Chen $L$, et al. Treatment with convalescent plasma for critically ill patients with SARSCoV-2 infection. Chest. 2020 Jul;158(1):e113.

41 Shen C, Wang Z, Zhao F, Yang Y, Li J, Yuan J, et al. Treatment of 5 critically ill patients with COVID19 with convalescent plasma. JAMA. 2020 Apr 28;323(16):1582-9.

42 Kong Y, Cai C, Ling L, Zeng L, Wu M, Wu Y, et al. Successful treatment of a centenarian with coronavirus disease 2019 (COVID-19) using convalescent plasma. Transfus Apher Sci. 2020 Oct;59(5):102820.

43 Ye M, Fu D, Ren Y, Wang F, Wang D, Zhang F, et al. Treatment with convalescent plasma for COVID-19 patients in Wuhan, China. J Med Virol. 2020 Oct;92(10):1890-1901.

44 Ahn JY, Sohn Y, Lee SH, Cho Y, Hyun JH, Baek YJ, et al. Use of convalescent plasma therapy in two COVID-19 patients with acute respiratory distress syndrome in Korea. J Korean Med Sci. 2020 Apr 13;35(14):e149.

45 Li L, Zhang W, Hu Y, Tong X, Zheng S, Yang $\mathrm{J}$, et al. Effect of convalescent plasma therapy on time to clinical improvement in patients with severe and life-threatening COVID-19: a randomized clinical trial. JAMA. 2020 Aug 4; 324(5):460-70.

46 Salazar E, Perez KK, Ashraf M, Chen J, Castillo B, Christensen PA, et al. Treatment of COVID-19 patients with convalescent plasma. Am J Pathol. 2020 Aug;190(8):1680-90.

47 Zeng Q-L, Yu Z-J, Gou J-J, Li G-M, Ma S-H, Zhang G-F, et al. Effect of convalescent plasma therapy on viral shedding and survival in patients with coronavirus disease 2019. J Infect Dis. 2020 Jun;222(1):38-43.

48 Anderson J, Schauer J, Bryant S, Graves CR. The use of convalescent plasma therapy and remdesivir in the successful management of a critically ill obstetric patient with novel coronavirus 2019 infection: a case report. Case Rep Womens Health. 2020;27:e00221.

49 Zhang L, Pang R, Xue X, Bao J, Ye S, Dai Y, et al. Anti-SARS-CoV-2 virus antibody levels in convalescent plasma of six donors who have recovered from COVID-19. Aging. 2020; 12(8):6536.

50 Rajendran K, Narayanasamy K, Rangarajan J, Rathinam J, Natarajan M, Ramachandran A. Convalescent plasma transfusion for the treatment of COVID-19: systematic review. J Med Virol. 2020 Sep;92(9):1475-83.
51 Pawar AY, Hiray AP, Sonawane DD, Bhambar RS, Derle DV, Ahire YS. Convalescent plasma: a possible treatment protocol for $\mathrm{CO}$ VID-19 patients suffering from diabetes or underlying liver diseases. Diabetes Metab Synd. 2020 Jul-Aug;14(4):665-9.

52 Martinez MA. Compounds with therapeutic potential against novel respiratory 2019 coronavirus. Antimicrob Agents Chemother. 2020 Apr 21;64(5):e00399-20.

53 GR K. Immune defenses. In: S B, editor. Medical microbiology. 4th ed. Galveston, TX: University of Texas Medical Branch at Galveston; 1996.

54 Tanne JH. Covid-19: FDA approves use of convalescent plasma to treat critically ill patients. BMJ. 2020;368:m1256.

55 Barone P, DeSimone RA. Convalescent plasma to treat coronavirus disease 2019 (COVID-19): considerations for clinical trial design. Transfusion. 2020 Jun;60(6):1123-7.

56 JS H. Drugmaker Takeda is Working on Coronavirus Drug. Accessed 2020 March 10. Available from: https://www.wsj.com/articles/drugmaker-takeda-is-working-on-coronavirus-drug-11583301660. Published March 4, 2020. Wall Street Journal. 2020.

57 Luke TC, Casadevall A, Watowich SJ, Hoffman SL, Beigel JH, Burgess TH. Hark back: passive immunotherapy for influenza and other serious infections. Crit Care Med. 2010; 38(4 Suppl):e66-73.

58 Menis M, Sridhar G, Selvam N, Ovanesov MV, Divan HA, Liang Y, et al. Hyperimmune globulins and same-day thrombotic adverse events as recorded in a large healthcare database during 2008-2011. Am J Hematol. 2013; 88(12):1035-40.

59 Gajic O, Rana R, Winters JL, Yilmaz M, Mendez JL, Rickman OB, et al. Transfusion-related acute lung injury in the critically ill: prospective nested case-control study. Am J Respir Crit Care Med. 2007;176(9):886-91.

60 Wan Y, Shang J, Sun S, Tai W, Chen J, Geng $\mathrm{Q}$, et al. Molecular mechanism for antibodydependent enhancement of coronavirus entry. J Virol. 2020 Feb 14;94(5):e02015-19.

61 Mair-Jenkins J, Saavedra-Campos M, Baillie JK, Cleary P, Khaw FM, Lim WS, et al. The effectiveness of convalescent plasma and hyperimmune immunoglobulin for the treatment of severe acute respiratory infections of viral etiology: a systematic review and exploratory meta-analysis. J Infect Dis. 2015;211(1): 80-90.

62 Crowe JE, Firestone CY, Murphy BR. Passively acquired antibodies suppress humoral but not cell-mediated immunity in mice immunized with live attenuated respiratory syncytial virus vaccines. J Immunol. 2001;167(7): $3910-8$.

63 Marano G, Vaglio S, Pupella S, Facco G, Catalano L, Liumbruno GM, et al. Convalescent plasma: new evidence for an old therapeutic tool? Blood Transfus. 2016;14(2):152. 
64 Li H, Liu S-M, Yu X-H, Tang S-L, Tang C-K. Coronavirus disease 2019 (COVID-19): current status and future perspective. Int J Antimicrob Agents. 2020 May;55(5):105951.

65 Cevik M, Bamford CGG, Ho A. COVID-19 pandemic-a focused review for clinicians. Clin Microbiol Infect. 2020;26(7):842-7.

66 Alfonso J, Rodriguez-Morales D, Katterine B-A, Ruchi T, Ranjit S, et al. COVID-19, an emerging coronavirus infection: current scenario and recent developments: an overview. J Pure Appl Microbiol. 2020;14(1):1-8.

67 Abd El-Aziza TM, Stockand JD. Recent progress and challenges in drug development against COVID-19 coronavirus (SARSCoV-2): an update on the status. Infect Genet Evol. 2020;83:104327.

68 Helena F F, Ron K, Daniella V-K, Rita C A, Barbara C, Eilam Y, et al. Immune-mediated approaches against COVID-19. Nature Nanotechnol. 2020;15:630-45.

69 Drożdżal S, Rosik J, Lechowicz K, Machaj F, Kotfis K, Ghavami S, et al. FDA approved drugs with pharmacotherapeutic potential for SARS-CoV-2 (COVID-19) therapy. Drug Resist Updat. 2020;53:100719.

70 Ströher U, DiCaro A, Li Y, Strong JE, Aoki F, Plummer F, et al. Severe acute respiratory syndrome-related coronavirus is inhibited by interferon-alpha. J Infect Dis. 2004;189(7): $1164-7$.
71 Pulido F, Arribas JR, Delgado R, Cabrero E, González-García J, Pérez-Elias MJ, et al. Lopinavir-ritonavir monotherapy versus lopinavir-ritonavir and two nucleosides for maintenance therapy of HIV. AIDS. 2008;22(2):F19.

72 Jones BM, Ma ES, Peiris JS, Wong PC, Ho JC, Lam B, et al. Prolonged disturbances of in vitro cytokine production in patients with severe acute respiratory syndrome (SARS) treated with ribavirin and steroids. Clin Exp Immunol. 2004;135(3):467-73.

73 Khamitov RA, Loginova SI, Shchukina VN, Borisevich SV, Maksimov VA, Shuster AM. Antiviral activity of arbidol and its derivatives against the pathogen of severe acute respiratory syndrome in the cell cultures. Vopr Virusol. 2008;53(4):9-13.

74 Wang M, Cao R, Zhang L, Yang X, Liu J, Xu $\mathrm{M}$, et al. Remdesivir and chloroquine effectively inhibit the recently emerged novel coronavirus (2019-nCoV) in vitro. Cell Res. 2020;30:269-71.

75 Bhimraj A, Morgan RL, Shumaker AH, Lavergne V, Baden L, Cheng VC-C, et al. Infectious Diseases Society of America guidelines on the treatment and management of patients with COVID-19. Clin Infect Dis. 2020 Apr 27:ciaa478.

76 Matthay MA, Goolaerts A, Howard JP, Lee JW. Mesenchymal stem cells for acute lung injury: preclinical evidence. Crit Care Med. 2010 Oct;38(10 Suppl):S569-73.
77 El Agha E, Kramann R, Schneider RK, Li X, Seeger W, Humphreys BD, et al. Mesenchymal stem cells in fibrotic disease. Cell stem cell. 2017;21(2):166-77.

78 Hammer Q, Rückert T, Romagnani C. Natural killer cell specificity for viral infections. Nat Immunol. 2018;19(8):800-8.

79 Chen H, Du Q. Potential natural compounds for preventing SARS-CoV-2 (2019-nCoV) infection. Preprints. 2020.

80 Lin CW, Tsai FJ, Tsai CH, Lai CC, Wan L, Ho TY, et al. Anti-SARS coronavirus 3C-like protease effects of Isatis indigotica root and plant-derived phenolic compounds. Antiviral Res. 2005;68(1):36-42.

81 Chen L, Li J, Luo C, Liu H, Xu W, Chen G, et al. Binding interaction of quercetin-3- $\beta$ galactoside and its synthetic derivatives with SARS-CoV 3CLpro: structure-activity relationship studies reveal salient pharmacophore features. Bioorg Med Chem. 2006; 14(24):8295-306.

82 Yi L, Li Z, Yuan K, Qu X, Chen J, Wang G, et al. Small molecules blocking the entry of severe acute respiratory syndrome coronavirus into host cells. J Virol. 2004;78(20):11334-9.

83 Chen F, Chan KH, Jiang Y, Kao RY, Lu HT, Fan KW, et al. In vitro susceptibility of 10 clinical isolates of SARS coronavirus to selected antiviral compounds. J Clin Virol. 2004; 31(1):69-75. 